ISSN 1112-9867

http://www.jfas.info

\title{
DESIGN OF AN AUTOMATIC SOLAR LIGHTING SYSTEM
}

S. S. Rais" , N. I. M. Enzai, N. Ahmad, N. Ahmed, R. Darus, Z. Jusoh, N. N. S. N. Dzulkefli, S. A. C. Kar, S. Mohamed, N. N. Mahzan, K. S. S .K. M. Noh and H. Husni

Faculty of Electrical Engineering, Universiti Teknologi MARA, 23000 Dungun, Terengganu, Malaysia

Published online: 17 October 2017

\begin{abstract}
Today, the worldwide research trends are heading towards producing environmental friendly outcomes. Thus, today the electricity is mostly generated from renewable sources such as sunlight, wind, tides and other to reduce dependency on non-renewable sources like hydroelectrics, fossil fuels and others. This paper presents an innovation of the automatic lighting system with the solar as a source of the system. Charger controller circuit is necessary to cut off the current of the rechargeable battery when reaching its maximum voltage. Dark-on relay circuit functions as an automatic switch to the light so that the light will be automatically turned on when there is no light or at night. Otherwise, the light will be turned off. The system can be applied to the room light, outdoor light, corridor light, spotlight or streetlight. The system is low cost and beneficial for home usage to save electricity bills and when the occupants are absent for relatively long period of time.
\end{abstract}

Keywords: renewable energy; solar energy; green technology; sustainable; dark on relay; automatic lighting system; analog electronic circuits; LDR

Author Correspondence, e-mail: sitisara851@tganu.uitm.edu.my

doi: http://dx.doi.org/10.4314/jfas.v9i5s.76 


\section{INTRODUCTION}

\subsection{Background}

The high increase in electricity demand is contributed by the usage of electrical appliances, buildings and lighting in residential areas, industries, governments, public areas and roads. Instead of that, it is also contributed by the cities development with the new buildings, houses and others. Fig. 1 shows the comparison of total electrical energy consumed by the world's top ten consumers in 2015 and 2016 with scales in TeraWatt hours (TWh) while Fig. 2 depicts the electrical energy consumed in Malaysia since 1990 to 2016 [3]. Both figures show that the yearly demand for electricity increases worldwide including Malaysia. It is believed that since the emergence of the Internet in 1990's, the usage of networking equipments, internet modems, computers and smart phones for home users and telecommunication providers have been contributing to the increment of the electricity utilization.

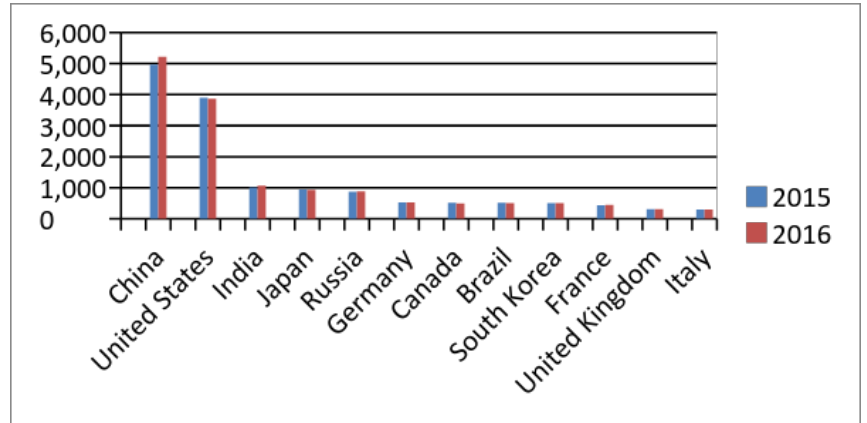

Fig.1. The comparison of total electrical energy consumed by the world's top ten consumers in 2015 and 2016 with scales in TeraWatt hours (TWh)

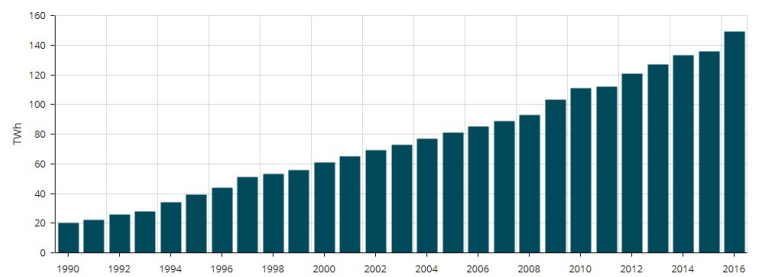

Fig.2. The electrical energy consumed in Malaysia since 1990 to 2016

Due to the increment of electrical energy consumption, the alternative sources have become alternatives implementation all over the world. The conventional resources for electricity generation are non-renewable energy such as hydroelectric and fossil fuel like coal, oil and 
natural gas. The use of fossil fuel is not sustainable because its formation takes billions of years, while hydroelectric can cause environmental damage. Therefore, awareness, research and utilization of renewable energy have been gaining attention since its emergence in the late 1990's [6]. One of alternative sources: the photovoltaic energy or solar cells has begun in 1876 when William Grylls Adams and his student, Richard Day, discovered that the selenium produced electricity when it is exposed to the sunlight [6]. Werner von Siemens who is an electricity expert stated that the discovery proved that the sunlight could be converted into electricity without heat or moving parts [6]. However, the solar industry began to develop in 1970s [6].

Data from Frankfurt School-UNEP Centre/BNEF Global Trends in Renewable Energy Investment 2015 shows that total global investment in renewable energy rose $5 \%$ in 2015 to USD286 billion which is more than 6 times higher compared to 2004 [5]. The investment from developing and developed countries are USD156 billion and USD130 billion respectively whereas the investment in fossil fuel, global investment was USD130 billion [5]. Additionally, it was the first time developing countries invested more than the developed countries. 2015 is a significant year for renewable energy [5].

The renewable energy becomes the worldwide trend today for sustainable development. Thus, this research also moves forward to achieve the same goal. Even though this research is a small scale technology, it impacts the household energy consumptions which leads to reduction of electricity bills.

\subsection{Literature Review}

[2] proposed a remote-control system to optimize management of street lighting system using Zigbee which interfaces with ARM microcontroller. The Zigbee transmitter and receiver are used to transfer information point-by-point and send to a control terminal for any actions. Light-dependent resistor (LDR) is used to turn on and off the light automatically. [1] designed an automatic street light control system using 8051 microcontroller. Their research also used LDR. The intensity of the light is controlled by Pulse Width Modulation (PWM) based on presence of vehicles using IR sensor. [4] used Arduino to control the brightness of the light with photoresistor which senses the amount of light in the surroundings. If the voltage from solar panel is more than $5 \mathrm{~V}$, the system will be turned off, meanwhile if the voltage is lower 
than $5 \mathrm{~V}$, the system will be turned on and the brightness of the light depends on the value received by the photoresistor. [7] designed a lighting system used in automobile with generated power through wheel and solar.

There are a lot of researches, projects and products that had been designed using solar energy. This paper highlights some innovations that provide multipurpose applications with low cost. Overall system is depicted in Fig. 3. The yellow box shows that the extra portion can be used for any other suitable application. The application that has been done in this paper is a lighting system where the controller used to switch on/off automatically is using LDR as a sensor.

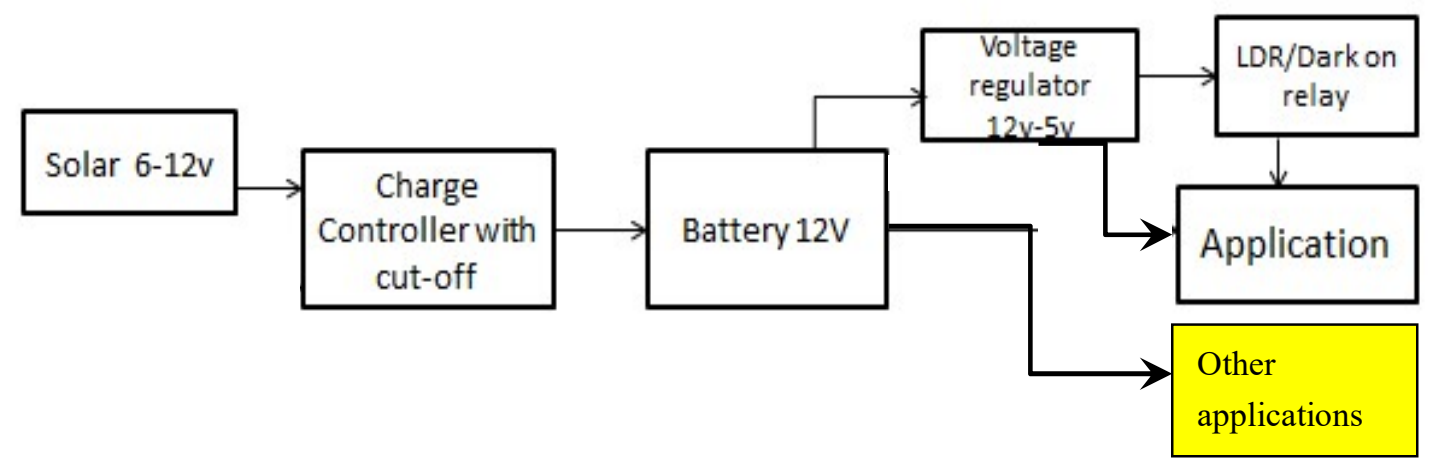

Fig.3. Scope of the research project

\section{METHODOLOGY}

The system comprises three divisions; solar charger controller circuit (Fig. 4), LDR circuit (Fig. 5) and application circuit. The solar charger controller circuit consists of solar cells (12V solar panel), rechargeable circuit and $12 \mathrm{~V}$ rechargeable battery. The system operates starting from solar cells capturing the sunlight and it is converted to electrical energy. The electrical energy is kept in the rechargeable battery through the rechargeable circuit. The rechargeable circuit functions to limit the excessive voltage and current from overflowing the battery. As mentioned in the previous section, the LDR circuit functions as an automatic switch to the light. 


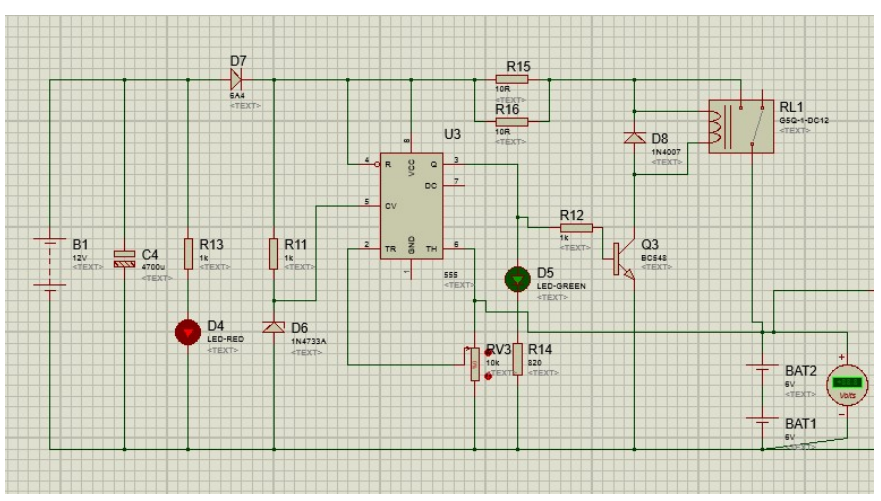

Fig.4. Solar charger controller circuit

The main component of the charger circuit controller is as depicted in Fig. 4 which is a 555 timer which compares the voltage in the battery. If the battery voltage is greater than $12 \mathrm{~V}$, the output of comparator and flip-flop inside 555 timer goes high and will be set (pin 3). Consequently, it will turn off the transistor and the relay. Contrarily, the relay will be turned on and the charging is processed when the battery voltage is lower than $12 \mathrm{~V}$.

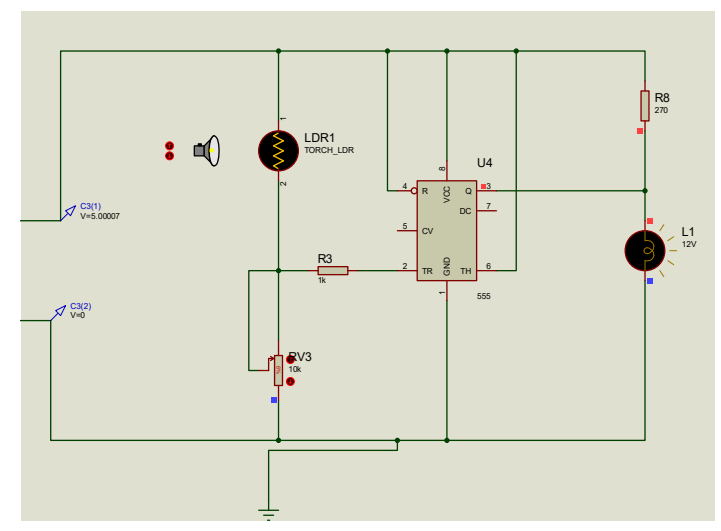

Fig.5. LDR circuit

For the sensing of surrounding luminance, the LDR circuit which is shown in Fig. 5 is designed by using 555 timer. The output of the timer (pin 3) is directly connected to the light (application part). This circuit is suitable for the low power of DC light. On the other hand, other circuit that consists of relay as in Fig. 6, namely dark-on relay is suitable for any range of lights. Nonetheless, for the purpose of renewable energy sources, the lights that can be used must be supported enough by the battery in terms of voltage and current. The supply for the 
light can be either a battery from a charger circuit or other solar battery.

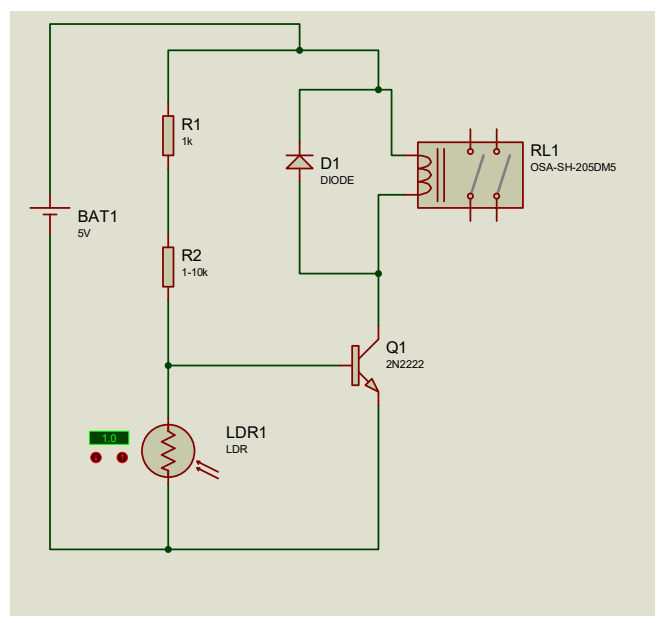

Fig.6. Dark-on relay circuit

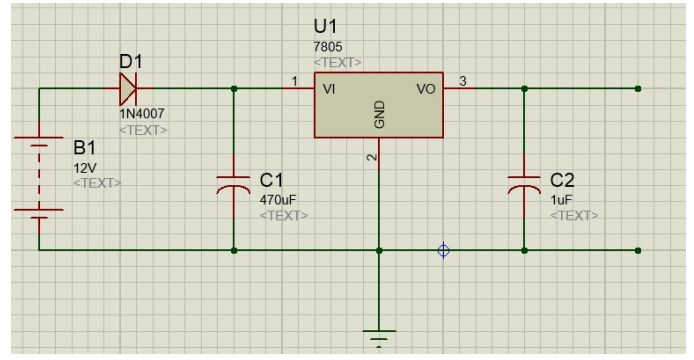

Fig.7. Voltage regulator circuit

This system uses $12 \mathrm{~V}$ rechargeable battery and only $5 \mathrm{~V}$ is utilized for the lighting system. Because of the application uses only $5 \mathrm{~V}$, the voltage regulator circuit needs to step-down the voltage as shown in Fig. 7. The 5V from voltage regulator will supply into LDR circuit and the application. The light will be turned on when LDR senses the dark condition and vice versa.

This system is also applicable for many other applications depending on the total power provided by the rechargeable battery, and can be expanded to the handphone charger for portability. The overall system is designed using analog electronic circuits and the prototype is of medium size. In the future, the design can be fabricated using microelectronics or implemented on surface mounted printed circuit board (PCB) and thus, the system size can be reduced for mobility purpose. Among the possible enhanced features are wireless monitoring 
system and brightness controller. However, the enhanced features will contribute to the increment of the cost.

\section{RESULTS AND DISCUSSION}

Fig. 8 is the final prototype of the system. There are a group of white LED lights that are placed at the top of the prototype while the circuits and the battery are placed at the bottom of the light. The light is operated automatically during day and night as depicted in Fig. 9. Fig. 9(a) and 9(b) show that the light is turned off during the day and the light is turned on during the night correspondingly. Fig. 10(a) and 10(b) show the measurement of the voltages taken on the output of the circuits; solar rechargeable and voltage regulator circuit. The output voltages for each circuit are $12 \mathrm{~V}$ and $5 \mathrm{~V}$.

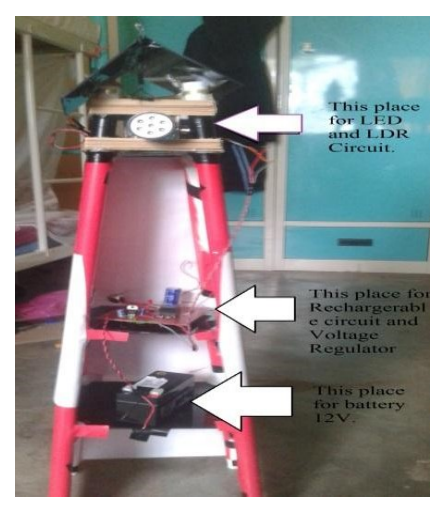

Fig.8. The prototype of the product

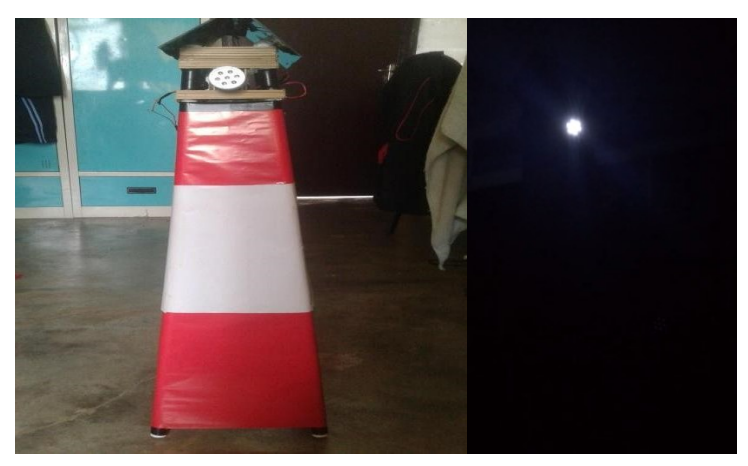

(a)

(b)

Fig.9. The output during the dark and daylight 


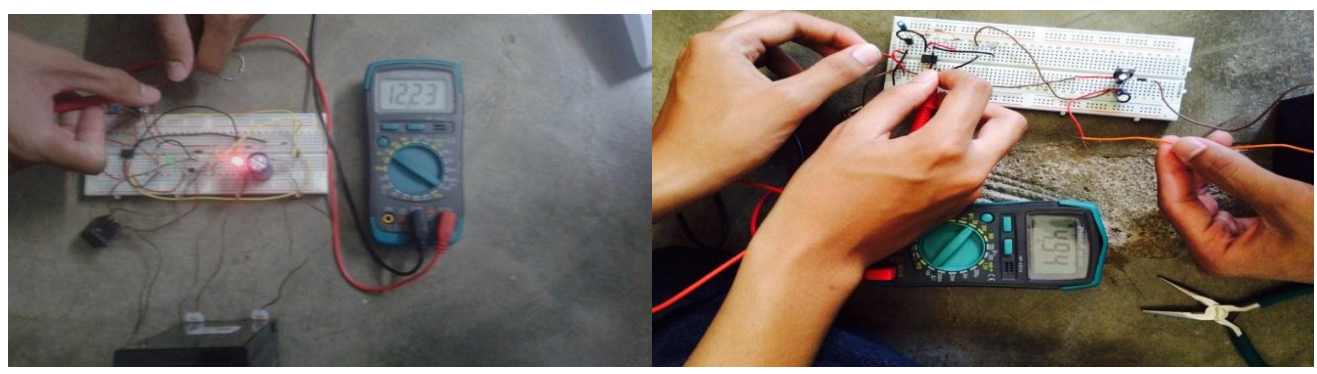

(a)

(b)

Fig.10. The measurement of voltage on the circuits (a) Output rechargeable battery (b) Output voltage regulator circuit

The total costs for this lighting system are about less than RM300 and it is lower compared to the other systems that use the microcontroller with enhanced features. The purchase of the $12 \mathrm{~V}$ solar panel with $852 \mathrm{~mW}$ and $12 \mathrm{~V} / 1.2 \mathrm{AH}$ Lead Acid battery costs about RM200 to RM220 which results to the highest contribution to the cost. The electronic components used for this system cost less than RM80.

The $12 \mathrm{~V}$ battery with $1.2 \mathrm{AH}$ can support many more lights or other applications that use USB port such as handphone and camera charger. It can also support speaker and CD player approximately $3 \mathrm{~W}$ and $7 \mathrm{~W}$ energy consumption. For further research, the maximum number of applications that can be supported by this system will be studied and the comparison of the electricity bills will be carried out.

\section{CONCLUSION}

The low cost and simple lighting system is designed with the solar panel as the main source of the battery. The battery charger circuit is necessary to cut off the excessive current and voltage that can harm the battery life. In this paper, the lighting system is based on the surrounding light. It is practical to be installed at roads, corridors, gardens, outdoors and rooms. This system does not provide monitoring system, brightness controller and other features to avoid extra cost. As an improvement of this system for home user, small modifications need to be done at the other applications part such as circuit for the USB connector that uses $5 \mathrm{~V}$ and the other lighting system to be used for the room or night lamp in the bedroom. It is also recommended that the relay in the charger circuit is replaced by the relay with 2 or more outputs. When the first rechargeable battery is fully charged, then it can switch to other 
battery for charging during the daylight. Thus, another rechargeable battery can be placed at the output relay of the charger circuit.

\section{ACKNOWLEDGEMENTS}

We thank our fellow labmates in for the stimulating discussions, for the helping during the laboratory works, and for all the fun we have had in the last year. In particular we are grateful to Faculty of Electrical Engineering, Universiti Teknologi MARA, Terengganu, Malaysia who had provided the facilities to accomplish the laboratory works.

\section{REFERENCES}

[1] Awale S, Sarode A, Patil D, Naik S, Deoghare P A. Solar street light using microcontroller. International Journal of Emerging Trends in Engineering and Management Research, 2016, 11(1)

[2] Bhargavi R, Pavitra B. Development of automatic street light illumination and vehicle speed controlling system on ARM7 for roadways. International Journal of Research in Advanced Engineering Technologies, 2016, 5(3):16-22.

[3] Enerdata. Electricity domestic consumption: Power consumption rebounded in 2016 (2\%), 2017

[4] Kaushik C, Singh S, Deswal V, Kaushik R, Jain A. Solar panel automatic brightness control system. Imperial Journal of Interdisciplinary Research, 2017, 3(6):175-178

[5] Myers J. 4 charts that show the rise of renewables, 2016

[6] Power-Star. (May 20, 2015). A brief history of Solar Energy, 2015

[7] Rohith B S, Reddy J D P, Maneiah D. Generating of power through wheels and solar with smart lighting system. International Journal of Innovative Technology and Research, 2016, 4(5):3817-3820

\section{How to cite this article:}

Rais S S, Enzai N I M, Ahmad N, Ahmed N, Darus R, Jusoh, Z, Dzulkefli N N S N, Kar S A C, Mohamed S, Mahzan N N, Noh K S S K M and Husni H. Design of an automatic solar lighting system. J. Fundam. Appl. Sci., 2017, 9(5S), 1097-1105. 